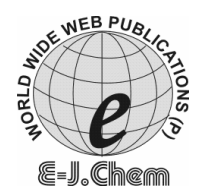

http://www.e-journals.net
ISSN: 0973-4945; CODEN ECJHAO

E-Journal of Chemistry

2009, 6(S1), S33-S40

\title{
Separation and Preconcentration of Copper Ion by Micelle-Mediated Extraction in Aqueous Samples
}

\author{
F. AHMADI ${ }^{\S}$, A. KHANMOHAMMADI ${ }^{\#}$ and Z. TAVAKOLI ${ }^{\S}$ \\ ${ }^{\S}$ Chemistry Department, \\ Gachsaran Azad University, Gachsaran, Iran. \\ "Young Researchers Club, \\ Gachsaran Azad University, Gachsaran, Iran. \\ ahmadi@iaug.ac.ir
}

Received 3 October 2008; Accepted 1 December 2008

\begin{abstract}
Cloud point extraction (CPE) has been used for preconcentration of copper after the formation of a complex with 5, 5-diphenylimidazolidine-2thione-,4-one (thiophenytoin) (DFID) and later analysis by flame atomic absorption spectrometry (FAAS) using octylphenoxypolyethoxyethanol (Triton $\mathrm{X}-114$ ) as surfactant. The chemical variables affecting the separation phase and the viscosity affecting the detection process were optimized. At $\mathrm{pH} 5.7 \pm 0.3$, preconcentration of only $15 \mathrm{~mL}$ of sample in the presence of $0.06 \%(\mathrm{w} / \mathrm{v})$ Triton $\mathrm{X}$ 114 and $1.5 \mathrm{mM}$ DFID permitted the detection limits of $1.5 \mathrm{ng} \mathrm{mL}^{-1}$ for copper. The enrichment factor was 39 for copper. The proposed method has been applied to the determination of copper in various samples and a standard reference material.
\end{abstract}

Keyword: 5-Diphenylimidazolidine-2-thione-,4-One (thiophenytoin) (DFID), Cloud point extraction, Copper ions, Triton X-114, Flame atomic absorption spectrometry.

\section{Introduction}

Several analytical techniques such as atomic absorption spectrometry (AAS), inductively coupled plasma atomic emission spectrometry (ICP-AES) and inductively coupled plasma mass spectrometry (ICP-MS) are available for the determination of trace metals with sufficient sensitivity for most of applications. However, the determination of trace metal ions in natural waters is difficult due to various factors, particularly their low concentrations and matrix effects. Preconcentration and separation can solve these problems and lead to a higher confidence level and easy determination of the trace elements by less sensitive, but more accessible Instrumentation such as flame atomic absorption spectrometry (FAAS) ${ }^{1}$ 
The use of micellar solutions in different areas of analytical chemistry has attracted much attention in recent years and separations based on cloud point extractions are becoming an important and practical application in the use of surfactants in analytical chemistry $^{2-5}$. Aqueous solutions of most non-ionic surfactants may become turbid when micellar solution is heated to a temperature known as the cloud point. Above this temperature the micellar solution separates into two transparent liquid phases. One of them, with the smallest volume (surfactant-rich phase), contains most of the surfactant whereas the other (referred to as the aqueous phase) contains a surfactant concentration close to critical micellar concentration $(\mathrm{cmc})$. The temperature at which phase separation occurs depends on the concentration of surfactant and the presence and concentration of both organic and inorganic additives ${ }^{6}$. The exact mechanism through which phase separation occurs remains to be fully elucidated and is attributed to the rapid increase in the aggregation number of the micelles as the temperature is increased. The cloud point phenomenon is reversible and when the temperature falls below the cloud point, a single phase appears again. Any hydrophobic species (hydrophobic organic compounds or metal ions after reaction with a suitable hydrophobic ligand). Originally present in water is able to react with and bind to micelles and become concentrated in a small volume of surfactant-rich phase. This unique phase separation phenomenon permits the design of simple schemes for extraction, preconcentration and purification, and has been reviewed by different workers ${ }^{7}$.

In the present work, we report the results obtained in a study of the cloud point preconcentration of copper, after preconcentration and separation with 5,5diphenylimidazolidine-2-thione-,4-one (thiophenytoin) (DFID), and later analysis by flame atomic absorption spectrometry using octylphenoxypolyethoxyethanol (TritonX-114) as surfactant. The proposed method is also applied to the determination of copper in various samples.

\section{Experimental}

The measurement of copper ion was performed with a 680 AA shimadzu spectrometer equipped with a copper hollow-cathode lamp as a radiation source was used throughout the measurement made at $324.8 \mathrm{~nm}$. The acetylene flow rate and the burner height were adjusted in order to obtain the maximum absorbance signal, while aspirating the analyte solution in methanol. The $\mathrm{pH}$ was determined with a Metrohm $691 \mathrm{pH} /$ ion meter with a combined glass-calomel electrode. An MP4 centrifuge (International Equipment Company, USA) was used to accelerate the phase separation.

\section{Materials}

All reagents used were of analytical-reagent grade. Stock solutions of $\mathrm{Cu}\left(1000 \mathrm{mg} \mathrm{L}^{-1}\right)$ and those used for the interference study $\left(100 \mathrm{mg} \mathrm{L}^{-1}\right)$ were prepared by dissolving appropriate amounts of their respective salts in doubly distilled water. The non-ionic surfactant Triton X-114 (Fluka Chemie AG, Switzerland) was used without further purification. The 5, 5diphenylimidazolidine-2-thione-, 4-one (thiophenytoin) (DFID) was synthesized according to the procedure given in the literature ${ }^{8}$.

\section{Procedure for cloud point extraction}

A typical cloud point experiment required the following steps: an aliquot of $15 \mathrm{~mL}$ of a solution containing $\mathrm{Cu}^{2+}, 0.06 \%(\mathrm{w} / \mathrm{v})$ Triton $\mathrm{X}-114$ and $1.5 \mathrm{mM}$ of DFID was adjusted to $\mathrm{pH}=5.7 \pm 0.3$ with a $\mathrm{HCl}$. The mixture was shaken for $1 \mathrm{~min}$ and left to stand in a thermostated bath at $40{ }^{\circ} \mathrm{C}$, for $20 \mathrm{~min}$. Separation of the phases was achieved by centrifugation at $4000 \mathrm{rpm}$ 
for $15 \mathrm{~min}$. The whole system was cooled in an ice-bath for 15 min that the surfactant rich phase would regain its viscosity. In this way, the bulk aqueous phase was easily decanted. The remaining micellar phase was dissolved in $0.5 \mathrm{~mL}$ of $0.5 \mathrm{M} \mathrm{HNO}_{3}$ in methanol and then the copper content was readily evaluated by FAAS.

\section{Pretreatment of real samples}

\section{Water}

Analysis of waste water sample for determination of copper ions content was performed as follows: $400 \mathrm{~mL}$ of sample was transferred to a beaker and $8 \mathrm{~mL}$ concentrated $\mathrm{HNO}_{3}$ and 3 $\mathrm{mL}$ of $30 \% \mathrm{H}_{2} \mathrm{O}_{2}$ were added for elimination and decomposition of organic compound. The sample solution while stirring was heated to one tenth of initial volume. After adjustment of sample $\mathrm{pH}$ to desired value the CPE were performed according to general described procedure $^{9}$.

\section{Blood}

Homogenized blood sample $(50 \mathrm{~mL})$ was weighed accurately and transferred into a $200 \mathrm{~mL}$ beaker and digested in the presence of oxidizing reagents $\left(25 \mathrm{~mL}\right.$ concentrated $\mathrm{HNO}_{3}$ and 5 $\mathrm{mL} \mathrm{HClO}_{4} 70 \%$ ) then heated for $1 \mathrm{~h}$. The beaker content was filtered through a Whatman \# 40 filter paper into a $250 \mathrm{~mL}$ volumetric flask and its $\mathrm{pH}$ was adjusted to desired value and diluted to mark with de-ionized water. Standard addition method was used for determination of copper in real samples.

\section{Vegetables}

All vegetable samples were purchased from Gachsaran Iran. Afterwards, they were taken in small mesh. A $50 \mathrm{~g}$ vegetable sample was heated in silica crucible for $3 \mathrm{~h}$ on a hot plate and the charred material was transferred to furnace for overnight heating at $650{ }^{\circ} \mathrm{C}$. The residue was cooled, treated with $12 \mathrm{~mL}$ concentrated nitric acid and $4 \mathrm{~mL} 30 \% \mathrm{H}_{2} \mathrm{O}_{2}$ again kept in a furnace for $2 \mathrm{~h}$ at the same temperature $\left(650^{\circ} \mathrm{C}\right)$ so that no organic compound traces are left. The final residue was treated with $3 \mathrm{~mL}$ of concentrated hydrochloric acid and $3-5 \mathrm{~mL}$ of $70 \%$ perchloric acid and evaporated to fumes, so that all the metals change to respective ions. The solid residue was dissolved in water, filtered and by keeping the $\mathrm{pH}$ at $5.7 \pm 0.3$ made up to $25 \mathrm{~mL}$ by addition of $\mathrm{KOH}$ and acetate buffer. The dissolved solution was suitably diluted and metal concentrations were determined after suitable preconcentration using $\mathrm{AAS}^{10}$.

\section{Results and Discussion}

Effect of $p H$

$\mathrm{CPE}$ of copper ion was performed in solutions of $\mathrm{pH}$ ranging from 2 to 8 . Separation of metal ions by cloud point method involves the prior formation of a complex with sufficient hydrophobicity to be extracted in to the small volume of surfactant-rich phase. Extraction recovery depends on the $\mathrm{pH}$ at which complex formation occurs. Figure 1 shows the effect of $\mathrm{pH}$ on the extraction of copper complex. It was found that at $\mathrm{pH}=5.5-6.0$ extraction is quantitative. Due to the presence of nitrogen atom in the ligand structures, which are weakly acid, at low $\mathrm{pH}$ they are not available to form chelate complexes and hydrogen ion compete with copper ion to these active sites, while in basic media due to hydroxide precipitation extraction efficiency would be reduced. 


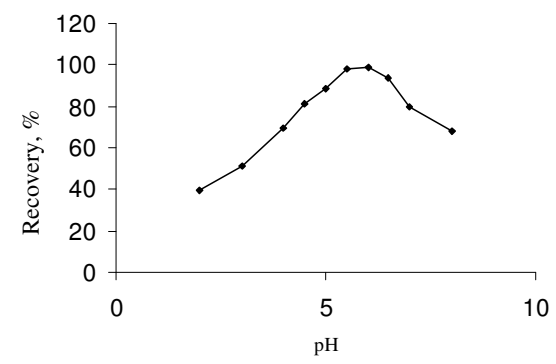

Figure 1. Effect of $\mathrm{pH}$ on copper ion extraction. Conditions: $15 \mathrm{~mL}$ of $0.2 \mu \mathrm{g} \mathrm{mL}^{-1} \mathrm{Cu}^{2+}$ ion at various $\mathrm{pH}$ values, $0.06(\mathrm{w} / \mathrm{v})$ Triton $\mathrm{X}-114,1.5 \mathrm{mM}$ DFID, 0.5\% (w/v) $\mathrm{NaCl}$, eluting solution $0.5 \mathrm{~mL}$ of $0.5 \mathrm{M} \mathrm{HNO}_{3}$ in methanol.

\section{Effect of DFID concentration}

The DFID was employed as a complexing agent for copper ion CPE. The concentration of DFID was evaluated over the range 0.5-4.0 mM. There was no significant difference in the results between 1.5-4.0 $\mathrm{mM}$ considering the average copper ion recovery. The extraction recovery as a function of the DFID concentration is shown in Figure 2. For this study, 15 $\mathrm{mL}$ of a solution containing $0.2 \mu \mathrm{g} \mathrm{mL} \mathrm{m}^{-1}$ copper ion in $0.06 \%(\mathrm{w} / \mathrm{v})$ Triton X-114 with various amounts of DFID was subjected to the cloud point preconcentration process. At this stated concentration of ion, $\sim 100 \%$ extraction was achieved for a DFID concentration of 1.5 $\mathrm{mM}$, which this concentration was chosen for subsequent experiments.

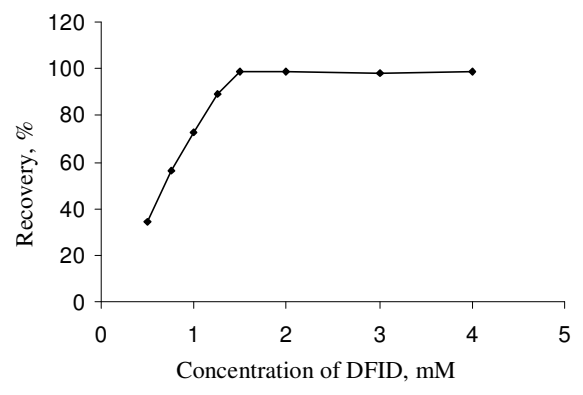

Figure 2. Effect of DFID concentration on copper ion extraction by CPE. Conditions: $15 \mathrm{~mL}$ of $0.2 \mu \mathrm{g} \mathrm{mL}^{-1} \mathrm{Cu}^{2+}$ ion at $\mathrm{pH} 5.7 \pm 0.3,0.06 \%(\mathrm{w} / \mathrm{v})$ Triton X-114, different concentration of DFID, $0.5 \%(\mathrm{w} / \mathrm{v}) \mathrm{NaCl}$, eluting solution $0.5 \mathrm{~mL}$ of $0.50 \mathrm{M} \mathrm{HNO}_{3}$ in methanol.

\section{Effect of triton $X-114$ concentration}

The preconcentration efficiency was evaluated using variable Triton X-114 concentrations ranging from $0.01 \%$ to $0.12 \%(\mathrm{w} / \mathrm{v})$. The results are demonstrated in Figure 3 . As it is seen, the highest copper ion recovery was obtained with $0.06 \%(\mathrm{w} / \mathrm{v})$ Triton X-114. By decreasing the surfactant concentration to $0.01 \%(\mathrm{w} / \mathrm{v})$ the recovery is reduced. The copper ion recovery also decreased for a Triton X-114 concentration greater than $0.06 \%(\mathrm{w} / \mathrm{v})$. This result might be related to the presence of the high amount of surfactant, resulting in an increase in the volume of the surfactant-rich phase. In addition, the viscosity of the surfactantrich phase increases, leading to poor sensitivity ${ }^{11,12}$. At lower Triton X-114 concentrations (below $0.01 \% \mathrm{w} / \mathrm{v}$ ), the preconcentration efficiency of the complex was very low, probably due to inability for quantitatively entrapment of hydrophobic complex ${ }^{13}$. So, $0.06 \%$ (w/v) of surfactant concentration was selected as optimum concentration of Triton X-114. 


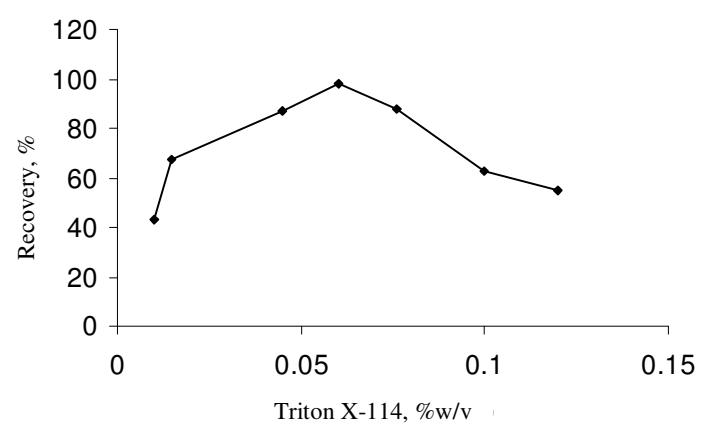

Figure 3. Effect of Triton X-114 concentration on copper ion extraction by CPE. Conditions: $15 \mathrm{~mL}$ of $0.2 \mu \mathrm{g} \mathrm{mL} \mathrm{mL}^{-1} \mathrm{Cu}^{2+}$ ion at $\mathrm{pH} 5.7 \pm 0.3,1.5 \mathrm{mM}$ DFID different concentration of TritonX-114, $0.5 \%(\mathrm{w} / \mathrm{v}) \mathrm{NaCl}$, eluting solution $0.5 \mathrm{~mL}$ of $0.50 \mathrm{M} \mathrm{HNO}_{3}$ in methanol.

\section{Effect of viscosity}

In order to facilitate the sample introduction in the FAAS nebulizer, it was necessary to decrease the surfactant-rich viscosity. Several organic solvents and their acid mixtures were investigated, to taking into account that these solvents increase the analytical signal of the FAAS ${ }^{14}$. Solvents tested include acetone, ethanol and methanol. Best results were obtained using methanol. A $0.5 \mathrm{~mol} \mathrm{~L}^{-1}$ nitric acid solution was added to methanol and $0.5 \mathrm{~mL}$ of this solution was used as diluent. In these conditions, the analytical signals were at a maximum.

\section{Effect of equilibration temperature and time}

The equilibration temperature above the cloud point and equilibration time was thoroughly optimized. It was desirable to employ the shortest equilibration time and the lowest possible equilibration temperature, a compromise between completion of extraction and efficient separation of the phases. Figure 4 clearly shows that a temperature of $40{ }^{\circ} \mathrm{C}$ is adequate for the experiment. At lower temperatures separation of the two phases is not complete. The dependence of extraction efficiency on equilibration time was studied for a time interval of 5-25 min. An equilibration time of $20 \mathrm{~min}$ was chosen to be optimal to achieve a quantitative extraction.

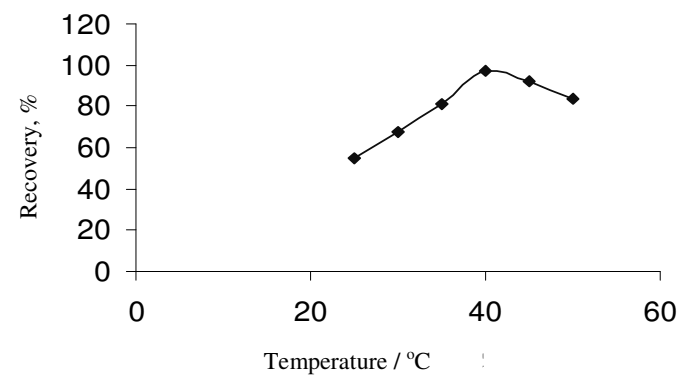

Figure 4. Effect of equilibration temperature on the cloud point extraction using DFID reagent of copper. Conditions: $15 \mathrm{~mL}$ of $0.2 \mu \mathrm{g} \mathrm{mL} \mathrm{m} \mathrm{Cu}^{2+}$ ion at $\mathrm{pH} 5.7 \pm 0.3,1.5 \mathrm{mM}, 0.06$ (w/v) Triton $\mathrm{X}-114$, DFID, $0.5 \%$ (w/v) $\mathrm{NaCl}$, eluting solution $0.5 \mathrm{~mL}$ of $0.50 \mathrm{M} \mathrm{HNO}_{3}$ in methanol. 


\section{Effect of centrifuge time and rates}

It is required to preconcentrate trace amount of copper ion with high efficiency in short time. Therefore, CPE on a set of experiments of $15 \mathrm{~mL}$ sample at $\mathrm{pH} 5.70 \pm 0.3,1.5 \mathrm{mM}$ DFID, $0.06(\mathrm{w} / \mathrm{v}) \%$ Triton $\mathrm{X}-114,0.2 \mu \mathrm{g} \mathrm{mL}{ }^{-1}$ copper(II) and $0.5 \%(\mathrm{w} / \mathrm{v}) \quad \mathrm{NaCl}$ by heating $40{ }^{\circ} \mathrm{C}$ and centrifuging in various rate and time further cooling in various time has been carried out. The results indicate the experiment in the optimized reagent concentration after heating for $20 \mathrm{~min}$ in $40{ }^{\circ} \mathrm{C}$ and centrifuging by $15 \mathrm{~min}$ in $4000 \mathrm{rpm}$ and cooling in $15 \mathrm{~min}$ in icebath lead to high recovery of copper ion in short time.

\section{Effect of ionic strength}

The addition of an inert salt can facilitate the phase-separation process for some nonionic surfactant systems, since it increases the density of the bulk aqueous phase. ${ }^{15,16}$ when the salt concentration is increased, the micelle size and the aggregation number are increased and the critical micellar concentration remains constant ${ }^{17}$. In addition, non-polar analytes may become less soluble in the solution at higher salt concentrations and thus contribute to higher recoveries. The results obtained indicate that the addition of salt produces an increase in the extraction of the more polar solutes while the recoveries of the less polar compounds are not affected. ${ }^{18-20}$ based on this discussion, $\mathrm{NaCl}$ was investigated as electrolyte in the concentration range from 0.1 to $1 \%(\mathrm{w} / \mathrm{v})$ and the highest copper ion recovery was obtained at $0.5 \%(\mathrm{w} / \mathrm{v}) \mathrm{NaCl}$ concentration. The signal decreased considerably for increasing $\mathrm{NaCl}$ concentrations $(0.6-1 \% \mathrm{w} / \mathrm{v})$. This effect might be explained by the additional surface charge when the $\mathrm{NaCl}$ concentration is very high, thus changing the molecular architecture of the surfactant and consequently the micelle formation process. It is necessary to emphasize that different blank solutions were also evaluated and no significant signal was obtained. In this way, $0.5 \%(\mathrm{w} / \mathrm{v}) \mathrm{NaCl}$ concentration was used in all further experiments.

\section{Characteristics of the method}

Calibration graph is obtained by preconcentration of different standard copper ion concentrations standard solution under the experimental conditions. The solutions were introduced into the flame by conventional aspiration. Table 1 gives the characteristic performance of the proposed method of standard solutions subjected to the entire procedure. Limits of detection and quantification according to IUPAC are also included. The limit of detection and the linear range of the proposed method are comparable to other methods that also employed FAAS. The characteristics of the proposed method are shown in Table 2.

Table 1. Optimum parameters of proposed method.

\begin{tabular}{lc}
\hline \multicolumn{1}{c}{ Parameter Optimum } & Value for copper \\
\hline $\mathrm{pH}$ & $5.7 \pm 0.3$ \\
Triton X-114(w/v) & $0.06 \%$ \\
Eluting agent & $0.5 \mathrm{~mL} 0.5 \mathrm{~mol} \mathrm{~L}^{-1} \mathrm{HNO}_{3}$ in $\mathrm{CH}_{3} \mathrm{OH}$ \\
DDTT concentration, $\mathrm{mM}$ & 1.5 \\
Bath temperature & $40{ }^{0} \mathrm{C}$ \\
Temperature time & $20 \mathrm{~min}$ \\
Centrifuge time & $15 \mathrm{~min}$ \\
Centrifuge rates & $4000 \mathrm{rpm}$ \\
\hline
\end{tabular}


Table 2. Specification of method at optimum conditions for copper.

\begin{tabular}{lc}
\hline \multicolumn{1}{c}{ Parameter } & copper \\
\hline Linear Range, $\mu \mathrm{g} \mathrm{mL}^{-1}$ & $0.01-1.5$ \\
Detection Limit, $\mathrm{ng} \mathrm{mL}^{-1}$ & 1.5 \\
RSD \% & 2.1 \\
Recovery \% & 99.4 \\
Enrichment factor & 39 \\
\hline
\end{tabular}

\section{Effect of foreign ions}

A study of potential interferences in the determination of copper was performed. An error of $\pm 5 \%$ in absorbance reading was considered tolerable. Solutions containing copper $\left(0.2 \mu \mathrm{g} \mathrm{mL}^{-1}\right)$ and other ions were prepared and the developed procedure was applied. The tolerance limits of various foreign ions are given in Table 3. These results demonstrate that the effects of other ions at given concentrations are negligible. Also, the Presence of large amounts of alkali and alkaline earth metals has no significant effect on the preconcentration of copper.

Table 3. Tolerance limit of foreign ions on copper $\left(0.2 \mu \mathrm{g} \mathrm{mL}^{-1}\right)$ determination by proposed procedure.

\begin{tabular}{cccc}
\hline ions $/ \mu \mathrm{g} \mathrm{mL}$ & Added As & Tolerance Limit Ion $/ \mu \mathrm{g} \mathrm{mL}$ & Recovery/\% \\
\hline $\mathrm{Cl}^{-1}, \mathrm{~K}^{+}, \mathrm{Na}^{+}$ & $\mathrm{KCl}, \mathrm{NaCl}$ & 1300 & 98.5 \\
$\mathrm{Zn}^{2+}, \mathrm{Cd}^{2+}, \mathrm{Co}^{2+}, \mathrm{Cr}^{3}$ & Nitrate salt & 850 & 101.3 \\
$\mathrm{Mg}^{2+}, \mathrm{Ca}^{2+}$ & $\mathrm{MgCl}_{2}, \mathrm{CaCl}_{2}$ & 800 & 99.3 \\
$\mathrm{Ni}^{2+}, \mathrm{Fe}^{2+}$ & Nitrate salt & 600 & 97.9 \\
$\mathrm{HCO}_{3}{ }^{-}$ & $\mathrm{NaHCO}_{3}$ & 300 & 98.9 \\
\hline
\end{tabular}

\section{Accuracy and applications}

We have explored the feasibility of the methodology using preconcentration with DFID in surfactant media for the determination of copper ion in different matrices treated according to experimental section. The procedure was applied to the determination of copper ion in different samples, including waste water, river water and blood samples and vegetable sample by standard addition method. Reliability was checked by spiking experiments and independent analysis. The results are presented in Table 4. The recoveries of spiked samples are satisfactory and were confirmed using standard addition method, which indicate the capability of the system in the determination of copper in various samples.

Table 4. Recovery studies of Copper in various Samples (N=3)

\begin{tabular}{ccccc}
\hline Sample & Added & Found & RSD \% & Recovery \% \\
\hline River water & 0 & 64.1 & 1.9 & - \\
& 100 & 164.3 & 1.1 & 100.2 \\
Tap water & 0 & 61.8 & 1.3 & - \\
& 100 & 161.9 & 1.1 & 100.1 \\
Waste water & 0 & 103.3 & 1.8 & - \\
& 100 & 203.8 & 1.2 & 100.5 \\
Vegetable & 0 & 127.4 & 1.7 & - \\
& 100 & 228.2 & 1.3 & 100.8 \\
Blood & 0 & 67.4 & 1.7 & - \\
& 100 & 169.6 & 1.9 & 102 \\
\hline
\end{tabular}




\section{Conclusion}

The combined advantages of the cloud point methodology (easy, safe, rapid and inexpensive) and the use of DFID as a reagent (selectivity and sensitivity) for $\mathrm{Cu}$ was utilized for their determination in various samples. The method gives a very low limit of detection and good R.S.D. values. The results of this study clearly show the potential and versatility of this method, which could be applied to monitoring $\mathrm{Cu}$ spectrophotometrically in various samples.

\section{References}

1. Ahmadi F, Khanmohammadi A, Niknam K and Jafarpour J, Eurasian J Analytical Chem., 2007 2(3), 118.

2. Pramauro E and Pelizzetti E, Surfactants in Analytical Chemistry, Applications of Organized Amphiphilic Media, Elsevier, New York, 1996, 178.

3. Cerrato Oliveros M C, Jimenez de Blas O, P'erez Pav'on J L and Moreno Cordero B, J Anal At Spectrom., 1998, 13, 547.

4. Mesquita da Silva M A, Azzolin Frescura V L, Nome Aguilera F J and Curtius A J, J Anal At Spectrom., 1998, 13, 1369.

5. Paleologos E K, Stalikas C D, Tzouwara-Karayanni S M, Pilidis G A and Karayannis M I, J Anal At Spectrom., 2000, 15, 287.

6. Tani H, Kamidate T and Watanabe H, J Chromatogr A., 1997, 780, 229.

7. Saitoh T, Tani H, Kamidate T and Watanabe H, Trends Anal Chem., 1995, 14, 213.

8. Ghaedi M, Ahmadi F, Tavakoli Z, Montazerozohori M, Khanmohammadi A and Soylak M, J Hazard Mater., 2008, 152(3), 1258.

9. Ghaedi M, Ahmadi F, Karimi, H and Gharaghani S, Korean J Chem., 2006, 1, 23.

10. Ghaedi M, Spectrochim Acta Part A. 2006, 63, 193.

11. Pinto C G, Pavo'́n J L P and Cordero B M, J Anal At Spectrom., 1996, 11, 37.

12. Tani H, Kamidate T and Watanabe T, J Chromatogr A., 1997, 780, 229.

13. Borges D L G, Veiga M A M S, Frescura V L A, Welz B and Curtius A J, J Anal At Spectrom., 2003, 18, 501.

14. Fang Z, Flow Injection Separation and Preconcentration, $1^{\text {st }}$ Ed., John Wiley: New York, 1993.

15. Saitoh T and Hinze W L, Anal Chem., 1991, 63, 2520.

16. Froschl B, Stangl G and Niessner R, Freseniu J Anal Chem., 1997, 22, 357.

17. Eiguren Fernández A, Sosa Ferrera Z and Santana Rodriguez J J, Quım. Anal., 1997, 16, 283.

18. Mahugo Santana C, Sosa Ferrera Z and Santana Rodriguez J J, Analyst (Cambridge, UK). 2002,127, 1031.

19. Eiguren Fernández A, Sosa Ferrera Z and Santana Rodriguez J J, Anal Chim Acta., 1998, 358, 145.

20. Eiguren Fernández A, Sosa Ferrera Z and Santana Rodriguez J J, Analyst (Cambridge, UK). 1999, 24, 487. 


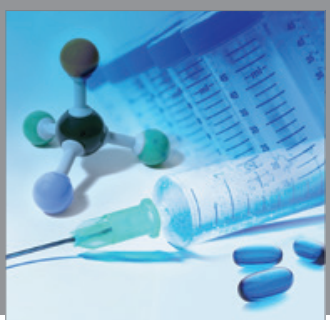

International Journal of

Medicinal Chemistry

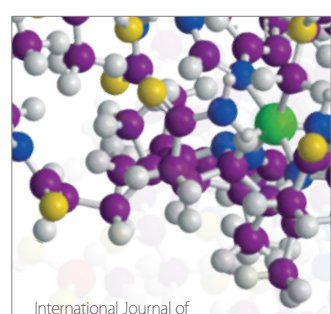

Carbohydrate Chemistry

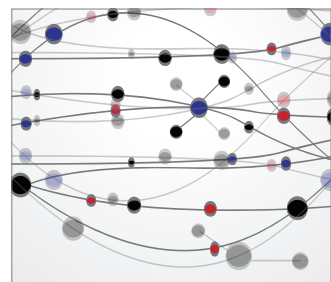

The Scientific World Journal
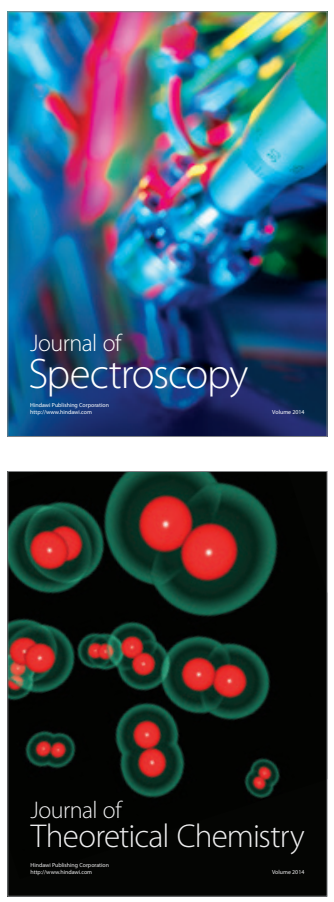
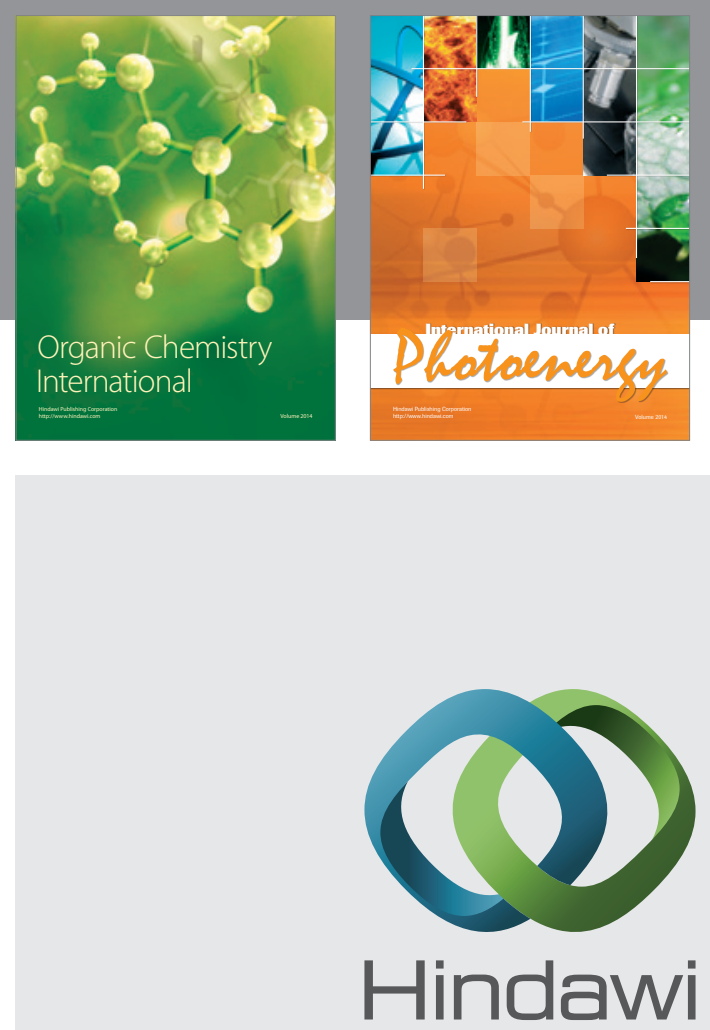

Submit your manuscripts at

http://www.hindawi.com
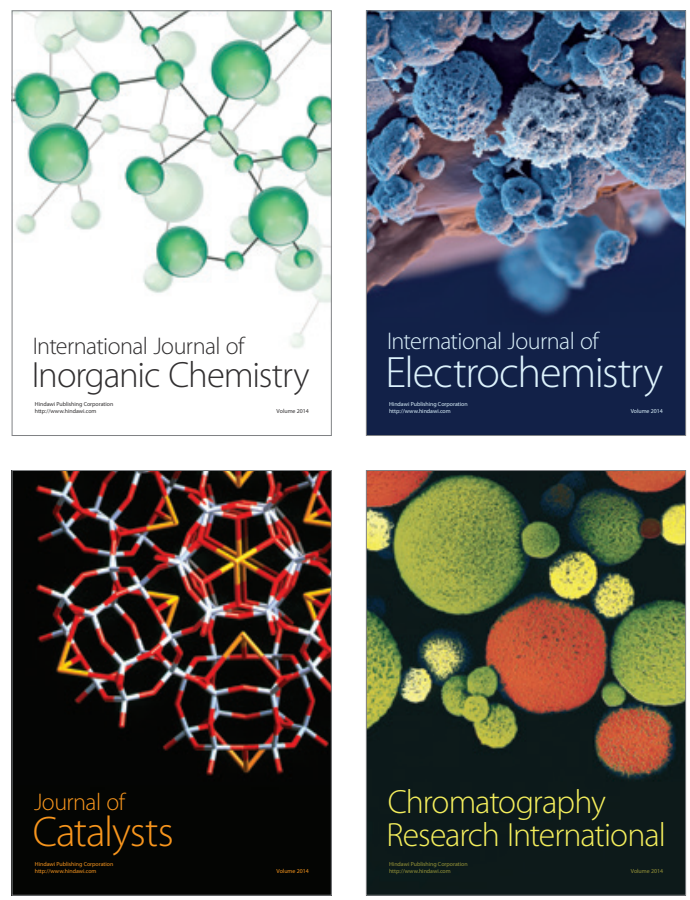
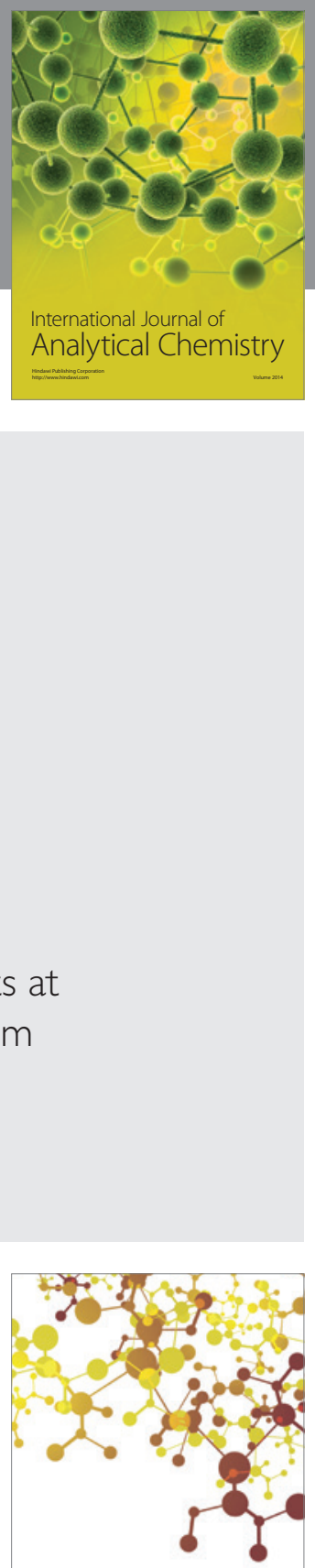

Journal of

Applied Chemistry
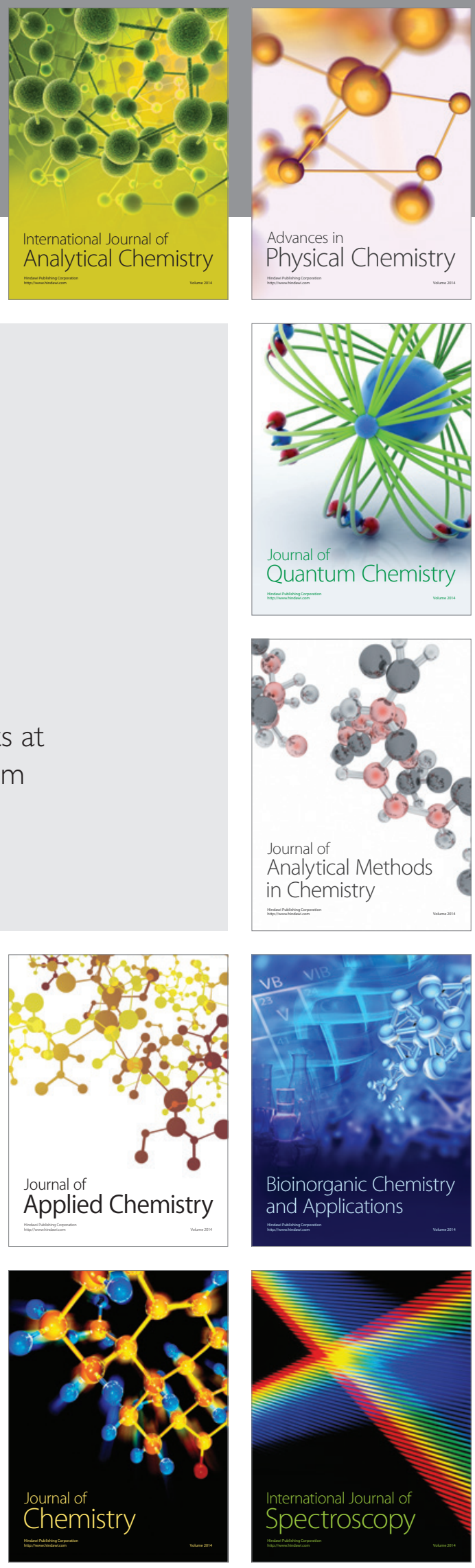